\title{
Atg8: an autophagy-related ubiquitin-like protein family
}

Tomer Shpilka', Hilla Weidberg', Shmuel Pietrokovski2* and Zvulun Elazar ${ }^{1 *}$

\begin{abstract}
Autophagy-related (Atg) proteins are eukaryotic factors participating in various stages of the autophagic process. Thus far 34 Atgs have been identified in yeast, including the key autophagic protein Atg8. The Atg 8 gene family encodes ubiquitin-like proteins that share a similar structure consisting of two aminoterminal a helices and a ubiquitin-like core. Atg 8 family members are expressed in various tissues, where they participate in multiple cellular processes, such as intracellular membrane trafficking and autophagy. Their role in autophagy has been intensively studied. Atg8 proteins undergo a unique ubiquitinlike conjugation to phosphatidylethanolamine on the autophagic membrane, a process essential for autophagosome formation. Whereas yeast has a single Atg8 gene, many other eukaryotes contain multiple Atg8 orthologs. Atg8 genes of multicellular animals can be divided, by sequence similarities, into three subfamilies: microtubule-associated protein 1 light chain 3 (MAP1LC3 or LC3), $\gamma$-aminobutyric acid receptor-associated protein (GABARAP) and Golgi-associated ATPase enhancer of $16 \mathrm{kDa}$ (GATE16), which are present in sponges, cnidarians (such as sea anemones, corals and hydras) and bilateral animals. Although genes from all three subfamilies are found in vertebrates, some invertebrate lineages have lost the genes from one or two subfamilies. The amino terminus of Atg8 proteins varies between the subfamilies and has a regulatory role in their various functions. Here we discuss the evolution of Atg8 proteins and summarize the current view of their function in intracellular trafficking and autophagy from a structural perspective.
\end{abstract}

\footnotetext{
*Correspondence: zvulun.elazar@weizmann.ac.il; Shmuel.Pietrokovski@weizmann.ac.il 'Department of Biological Chemistry, The Weizmann Institute of Science, 76100 Rehovot, Israel

2Department of Molecular Genetics, The Weizmann Institute of Science, 76100 Rehovot, Israel
}

\section{Gene organization and evolutionary history}

Autophagy-related 8 proteins (Atg8s) are one of the 62 highly conserved eukaryote-specific protein families [1]. Whereas yeast and other fungal species have a single Atg8 gene, multicellular animals, green plants and some protists have several. Animal Atg8 proteins comprise three subfamilies: microtubule-associated protein 1 light chain 3 (MAP1LC3, hereafter referred to as LC3), $\gamma$-aminobutyric acid receptor-associated protein (GABARAP) and Golgi-associated ATPase enhancer of $16 \mathrm{kDa}$ (GATE-16) (Figure 1a). Humans have a single GATE-16 gene, two GABARAP genes and four LC3 genes (Table 1). In addition, $L C 3 A$ encodes two isoforms resulting from alternative splicing. All three subfamilies are also present in diverse other bilateral species and in the earlier diverging animals - cnidarians (such as sea anemones, corals and hydras) and sponges. Atg8 genes have been both duplicated and lost during evolution, leading to the extinction and expansion of some subfamilies in specific lineages (Table 2). One example is in arthropods: the blacklegged tick Ixodes scapularis (an arachnid) [2] has GATE-16, GABARAP and LC3 genes, but in insects, the honey bee Apis mellifera has only a GABARAP and an LC3 gene [3] and the fruit fly Drosophila has two GABARAP genes [4]. One of the fruit fly GABARAP genes has no coding region introns and could be the result of a retrotransposition of the other gene's transcript during the emergence of the fruit flies. The human LC3 gene MAP1LC3B2 also lacks coding region introns and its coding region has 376 out of 378 bases identical with the human gene $M A P 1 L C 3 B$, which has three coding region introns and is more than $10 \mathrm{~kb}$ long (Table 1). The human genome also includes intron-less copies of all three ATG8 gene subfamilies, which are apparently inactive as a result of frameshifts and nonsense mutations.

Each Atg8 subfamily has some distinct sequence features (Figure 1b). For example, position 18 of the GATE-16 subfamily is typically a serine and sometimes an alanine residue. The corresponding position in the GABARAP subfamily, 18, is an invariant glycine residue, and in the LC3 subfamily the corresponding position, 20, is typically hydrophobic (a valine or alanine residue), and 

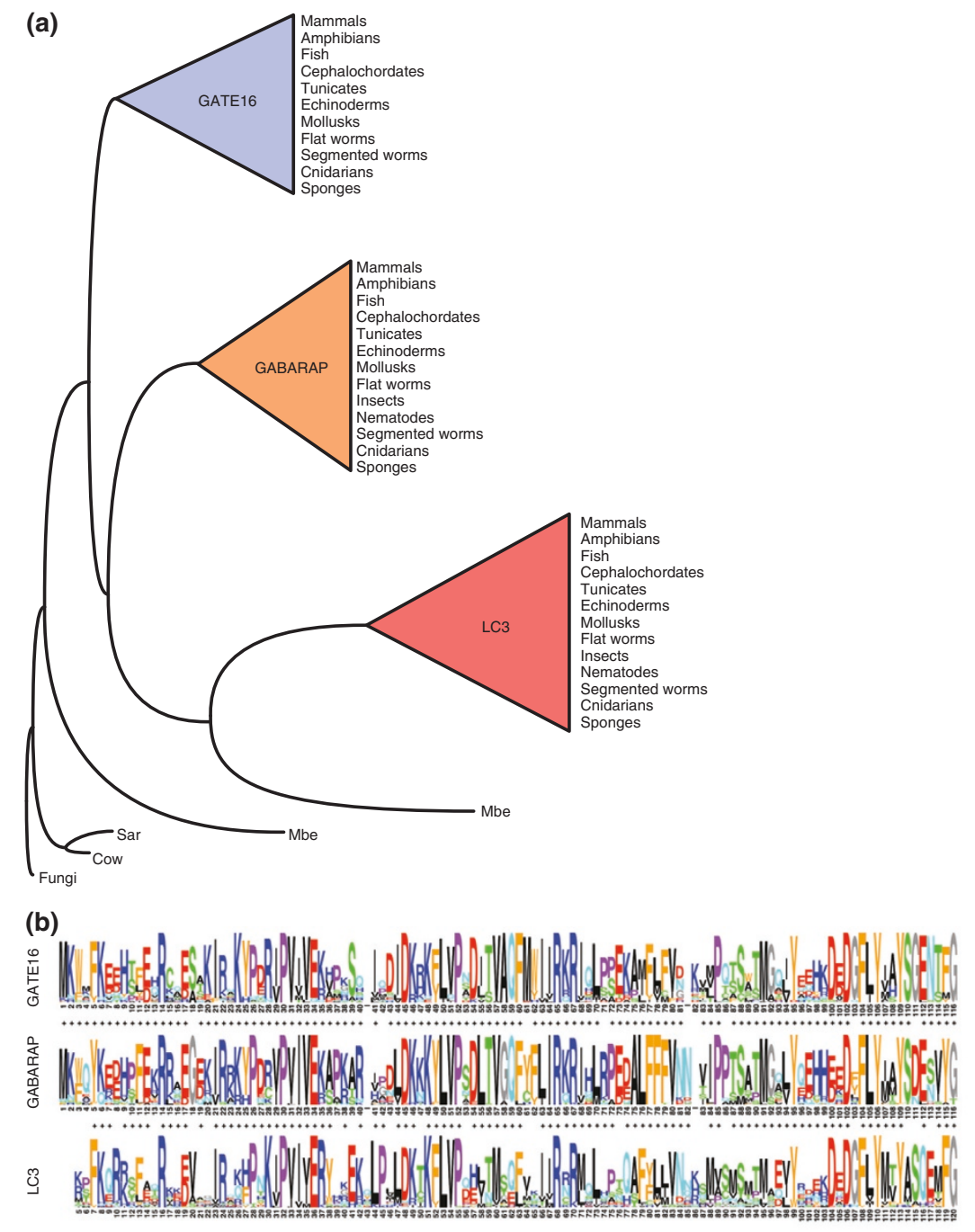

Figure 1. Evolution and sequence features of Atg8 genes. (a) Atg8 genes in fungi, animals and intermediate-branching species. A schematic tree, based on a sequence-derived phylogenetic tree, showing the three animal Atg8 subfamilies and their presence in key lineages. The subfamilies appear only in animals. Branching between animals and fungi are Atg8 proteins from the few known unicellular species that diverged after the emergence of fungi and before the emergence of multicellular animals. Shown here are Atg8 proteins from the choanoflagellate Monosiga brevicollis (Mbe) [6], the ichthyosporean Sphaeroforma arctica (Sar) and the amoeba Capsaspora owczarzaki (Cow) [111]. The scheme is based on a tree calculated from protein multiple alignment of Atg8 proteins from representative species with complete and almost complete genomic data. The alignment included 117 conserved amino acid positions. The tree was calculated using the PhyML program version 2.4.4, with 100 bootstrap replicates, four substitution rate categories, the HKY nucleotide substitution model and program-estimated Ts/Tv ratios, gamma shape parameters and invariant proportions as previously described [112]. The subfamily clusters are supported by bootstrap values ranging from 37/100 to 95/100 and also appeared with significant bootstrap values in other trees similarly calculated with different sets of Atg8 genes. The representative species for this scheme were: human, Danio rerio, Xenopus tropicalis, Branchiostoma floridae, Ciona savignyi, Oikopleura dioica, Strongylocentrotus purpuratus, Aplysia californica, Schistosoma mansoni, Schmidtea mediterranea, Drosophila melanogaster, Caenorhabditis elegans, Capitella teleta, Nematostella vectensis, Trichoplax adhaerens, Amphimedon queenslandica, Monosiga brevicollis, Sphaeroforma arctica, Capsaspora owczarzaki, Saccharomyces cerevisiae, Schizosaccharomyces pombe, Allomyces macrogynus, and Tuber melanosporum. (b) Atg8 subfamily sequence features. Sequence logos [113] show the conservation (overall height) and residue prevalence of multiple alignment positions. The alignment includes the core conserved sequence regions, only excluding short non-conserved distal regions of some sequences. The subfamilies are numbered by the coordinates of the human GATE-16, GABARAP and LC3 proteins. Plus signs indicate similar positions between alignments of the GATE-16 and GABARAP subfamilies and between the GABARAP and LC3 subfamilies. Each of the three families is very well conserved across its entire length (apart from the few aminoterminal residues in LC3). The three families are also very similar to each other in most of their positions. The few positions that are only conserved in each family and different between the subfamilies may account for some of the functional differences between the subfamilies. The alignments and logos were constructed as previously described [112], taking into account sequence redundancy and expected amino acid frequencies. Sequences for the alignments were taken from the CDD [114] and PFAM [115] database entries cd01611 and PF02991, respectively, and sequences similar to ones in these entries, from protein sequences and translated genomic and EST sequences found in public sequence databases. 
Table 1. Human ATG8 genes

\begin{tabular}{llccc}
\hline Subfamily & Gene names & Chromosome location & Gene size (kb)* & Coding region introns \\
\hline GATE-16 & GATE-16/GABARAPL2/GEF2 & $16 q 22.1$ & 10.9 & 3 \\
GABARAP & GABARAPL1/GEC1 & $12 p 13.31$ & 8.7 & 3 \\
& GABARAP & $17 p 13.1$ & 1.5 & 3 \\
LC3 & MAPILC3A & $20 q 11.22$ & 1.0 & 3 \\
& MAP1LC3B & $16 q 24.2$ & 10.7 & 3 \\
& MAPILC3B2 & $12 \mathrm{q} 24.22$ & 0.4 & 0 \\
& MAPILC3C & $1 \mathrm{q} 43$ & 2.8 & 3 \\
\hline
\end{tabular}

*Gene sizes are given from the start to the end of the protein coding region, without $5^{\prime}$ and $3^{\prime}$ UTRs (because their distal ends can be difficult to determine).

Table 2. Atg8 subfamilies in metazoan lineages

\begin{tabular}{|c|c|c|c|c|}
\hline \multirow[b]{2}{*}{ Lineage } & \multirow[b]{2}{*}{ Representative species } & \multicolumn{3}{|c|}{ Number of genes } \\
\hline & & GATE-16 & GABARAP & LC3 \\
\hline Mammals & Human & 1 & 2 & 4 \\
\hline Amphibians & Xenopus tropicalis (Western clawed frog) & 1 & 1 & 4 \\
\hline Fish & Danio rerio (zebrafish) & 1 & 3 & 4 \\
\hline Cephalochordates & Branchiostoma floridae (amphioxus) & 1 & 1 & 2 \\
\hline Tunicates & Ciona savignyi (Pacific transparent sea squirt) & 1 & 1 & 2 \\
\hline Echinoderms & Strongylocentrotus purpuratus (California purple sea urchin) & 2 & 1 & 2 \\
\hline Mollusks & Aplysia californica (California sea slug) & 1 & 1 & 2 \\
\hline Flat worms & $\begin{array}{l}\text { Schmidtea mediterranea (planarian) } \\
\text { Schistosoma mansoni (trematode) }\end{array}$ & $\begin{array}{l}1 \\
1\end{array}$ & $\begin{array}{l}1 \\
1\end{array}$ & $\begin{array}{l}1 \\
-\end{array}$ \\
\hline Nematodes & Caenorhabditis elegans & - & 1 & 1 \\
\hline Segmented worms & Capitella teleta & 1 & 1 & 2 \\
\hline Cnidarians & Nematostella vectensis (starlet sea anemone) & 1 & 1 & 2 \\
\hline Sponges & Amphimedon queenslandica & 2 & 1 & 2 \\
\hline
\end{tabular}

only sometimes a serine residue. Positions 40 in GABARAP and 42 in LC3 subfamilies are conserved and typically basic, whereas the GATE-16 family position corresponding to them, 40, is not well conserved and includes basic residues only in some proteins. At present it is unclear what functions, if any, are associated with these sequence features. Sponges, the oldest surviving basal multicellular animals [5], have genes from all three ATG8 subfamilies. Choanoflagellates, unicellular species that are the closest known relatives of animals [6], have ATG8 genes that do not belong to the three metazoan subfamilies (Figure 1a). It thus seems that the ATG8 gene family diverged into its three subfamilies during the emergence of multicellular animals, and that although the subfamilies underwent further expansion in some lineages, in other lineages some subfamilies were lost. In higher plants the ATG8 genes have also diverged, with Arabidopsis thaliana including eight such genes that can be grouped into three clusters. Different $A$. thaliana ATG8 genes showed distinct spatial and temporal expression patterns in different tissues [7].

\section{Characteristic structural features}

The structures of several Atg8 family members have been solved for mammals, yeast, invertebrates and the parasite Trypanosoma brucei [8-15]. These studies showed that all Atg8 proteins share a strong structural similarity to ubiquitin, despite the lack of similarity in amino acid sequence. GATE-16, the first Atg8 to be crystallized, contains two amino-terminal $\alpha$-helices in addition to its carboxy-terminal ubiquitin core [13]. Subsequent studies confirmed that these features are a unique characteristic of all Atg8 proteins [8-15] (Figure 2). The two aminoterminal $\alpha$ helices differ between the various mammalian Atg8 proteins; thus, for example, the first $\alpha$ helix of the LC3 subfamily is strongly basic, whereas in the GABARAP and GATE-16 subfamilies this region is acidic [15]. The ubiquitin core of the Atg8 proteins consists of a four-stranded central $\beta$ sheet, in which the two central strands are parallel to each other and the two outer strands are antiparallel to the central strands. Between these strands lie two $\alpha$ helices: $\alpha 3$ between $\beta 2$ and $\beta 3$, and $\alpha 4$ between $\beta 3$ and $\beta 4$ [16]. This domain contains a basic 


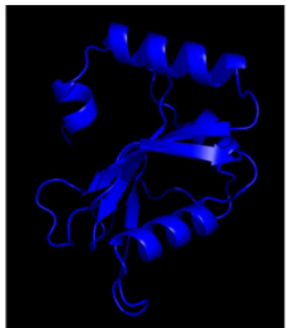

Gate-16

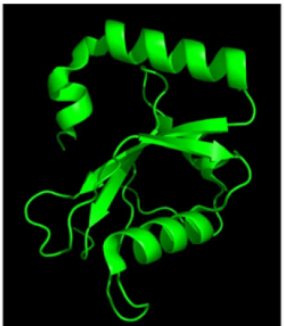

GABARAP

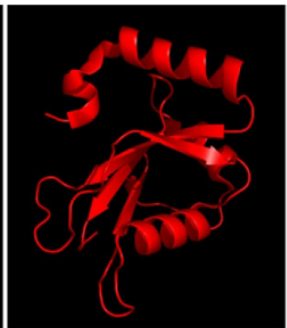

LC3B

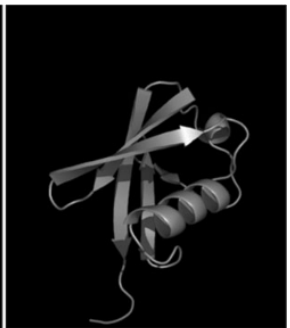

Ubiquitin

Figure 2. Crystal structures of the Atg8 family members and ubiquitin. All Atg8s share a similar ubiquitin-like fold with two additional aminoterminal a helices. GATE-16 is shown in blue (Protein Data Bank (PDB): 1EO6), GABARAP in green (PDB: 1KOT), LC3B in red (PDB: 1V49) and ubiquitin in gray (PDB: 1UBI). Helix shape represents an a helix; arrow shape represents a $\beta$ sheet; arrowhead represents the carboxyl termini of $\beta$ sheets.

feature that is conserved among family members and is suggested to have a role in protein-protein interactions. The molecular surface lying on the opposite side of the three-dimensional structure is poorly conserved and might mediate interactions specific to different Atg8 proteins [17], whereas the conserved domain is probably responsible for characteristic interactions of Atg8 proteins, such as binding to the conjugation machinery proteins.

During the autophagic process Atg8 proteins bind to numerous factors, such as proteins and possibly membranes [18]. A study by Coyle et al. [8] provides structural evidence for conformational changes resulting from protein-protein interactions. GABARAP was found to have two distinct conformations: a closed conformation, in which the $\alpha$ helices project down towards the surface of the ubiquitin core, and an open conformation, in which the ten amino-terminal amino acids are directed away from the ubiquitin core. The latter conformation is stabilized by the oligomeric state of the protein and points to flexibility in the Atg8 amino-terminal region. A conformational change was also reported in an in vitro reconstitution assay of yeast Atg8, in which accessibility of the amino terminus to antibody increased on conjugation of Atg8 to phosphatidylethanolamine (PE)-containing liposomes [19]. Taken together, these findings suggest that the Atg8 amino-terminal region has a crucial role in the functions of these proteins [20-22]. Differences between the various Atg8 proteins in this region might reflect their distinct functions. The amino-terminal region might also be a target for post-translational regulation.

\section{Localization and function Gene expression}

Atg8 proteins seem to be ubiquitously expressed, although some subfamily members are expressed at increased levels in certain tissues. The signaling pathways and transcription factors regulating their expression are only partially characterized. Of the LC3 subfamily, $L C 3 C$, which is transcribed at lower levels than other members of this subfamily, is expressed predominantly in the lung $[23,24]$. Expression analysis of the different GABARAP proteins reveals a distinct pattern: GABARAP-L1 is expressed predominantly in the central nervous system, similar to GATE-16, which is strongly expressed in the brain, whereas the expression of GABARAP is more marked in the endocrine glands [25,26].

Upregulation of Atg8s is observed under various stress conditions [27-30]. Although the transcriptional regulation of Atg8 genes is largely unknown, several reports have shown that the transcription factors FoxO1, FoxO3 and E2F1 regulate Atg8s in this process in mammalian cells [31-34]. Deciphering the expression patterns of specific Atg8 genes at transcriptional and translational levels may shed new light on their different physiological roles.

\section{The role of Atg8 in intracellular trafficking processes}

Atg8s were originally implicated in membrane trafficking processes [35]. Members of this protein family were initially connected to the SNARE fusion machinery that mediates the vast majority of intracellular trafficking processes. The AAA ATPase N-ethylmaleimide sensitive factor (NSF) promotes the disassembly of the SNARE complex, a step essential for multiple membrane fusion events. GATE-16 was characterized as a factor essential for intra-Golgi protein transport and was later shown to modulate this process by coupling NSF activity and the Golgi SNARE factor GOS-28 [26,36,37]. LC3 was first characterized as a protein that co-purified with microtubule-associated proteins $1 \mathrm{~A}$ and $1 \mathrm{~B}[38,39]$, but no direct involvement of this protein in membrane trafficking processes has been reported. GABARAP, however, was identified as a cytosolic protein that is localized to transport vesicles, the Golgi network and the endoplasmic reticulum (ER) and that interacts with the $\gamma 2$ subunit of $\mathrm{GABA}(\mathrm{A})$ receptors [40]. This interaction is thought to be essential for trafficking of the GABA(A) receptor to the plasma membrane [41]. A recent study showed that $\mathrm{GABA}(\mathrm{A})$ receptor trafficking is dependent 


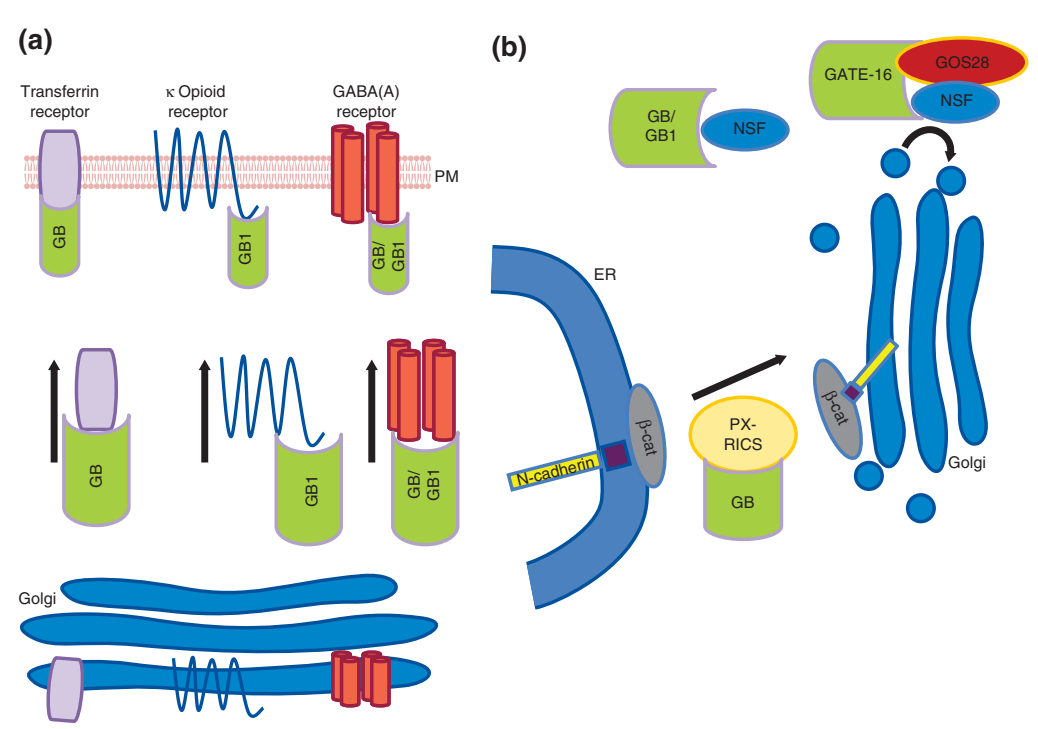

Figure 3. Role of Atg8 proteins in intracellular trafficking processes. (a) The GABARAP subfamily members GABARAP (GB) and GABARAP-L1 (GB1) participate in the transport of plasma membrane proteins, such as the GABA(A), K-opioid and transferrin receptors, from the Golgi to the plasma membrane (PM). (b) The GABARAP and the GATE-16 subfamilies both participate in transport from the ER to the Golgi and within the Golgi apparatus. GABARAP, together with PX-RICS, participates in N-cadherin/B-catenin transport from the ER to the Golgi. GATE-16 has been implicated in intra-Golgi transport through its interaction with Golgi SNARE protein 28 (GOS-28). Both subfamilies can interact with NSF, suggesting that they participate in regulation of membrane fusion events.

on processing of the GABARAP carboxyl terminus [42]. GABARAP's involvement in vesicle transport is not limited to the GABA(A) receptor; other plasma membrane proteins, such as the transferrin receptor, interact with GABARAP, although the role of GABARAP in their transport is not well established [43]. Moreover, ER-toGolgi transport is also controlled by GABARAP, as it interacts with PX-RICS, which is involved in transport of synaptic proteins to the ER. It has been suggested that these factors mediate the transport of the transmembrane protein $\mathrm{N}$-cadherin and its receptor $\beta$-catenin from the ER, thus controlling cell-cell adhesion [44]. The role of GABARAP in intracellular transport is also supported by its interaction with NSF, a component essential for SNARE-mediated fusion [41,45]. Similar to LC3, GABARAP binds to tubulin through its amino-terminal region, an interaction that regulates clustering of GABA(A) receptors [8,46,47].

Like GABARAP, GABARAP-L1 has been shown to interact with the GABA(A) receptor and tubulin in brain extracts, as well as with NSF $[48,49]$. GABARAP-L1 also binds directly to the G-protein-coupled $\mathrm{k}$-opioid receptor and mediates its transport in a manner dependent on modification of the carboxyl terminus [48,50,51]. The role of mammalian Atg8s in intracellular trafficking processes is depicted in Figure 3.

Consistent with the involvement of mammalian Atg8s in membrane fusion events, the yeast Pichia pastoris
Atg8 was recently found to mediate vacuolar fusion during adaptation from glucose- to methanol-containing medium [52]. This activity might involve the previously reported interaction of Atg8 with SNAREs in the yeast system [53].

To summarize, the mammalian GABARAP and GATE-16 subfamilies and the yeast Atg8 have been implicated in intracellular protein trafficking, but their exact role in these processes is not fully understood. The current consensus suggests that these molecules mediate trafficking both by escorting individual cargo molecules and possibly as regulators of membrane fusion events.

\section{Atg8 proteins are key cytoplasm-to-vacuole targeting and autophagic factors}

The first link between Atg8 proteins and autophagy was established in Saccharomyces cerevisiae, where the single Atg8 protein was identified as an autophagy and cytoplasm-to-vacuole targeting essential factor [54-56]. Cytoplasm-to-vacuole targeting is responsible for transporting vacuolar protein residents, such as aminopeptidase I (Ape1) and $\alpha$-mannosidase (Ams1), to the vacuole $[57,58]$. In yeast, Atg8 expression is upregulated during nitrogen starvation and is degraded in the vacuole following recruitment into autophagosomes [59]. Subsequent to its translation, Atg8 undergoes several modifications, starting with cleavage in its carboxy-terminal region to expose a glycine residue. This cleavage is 


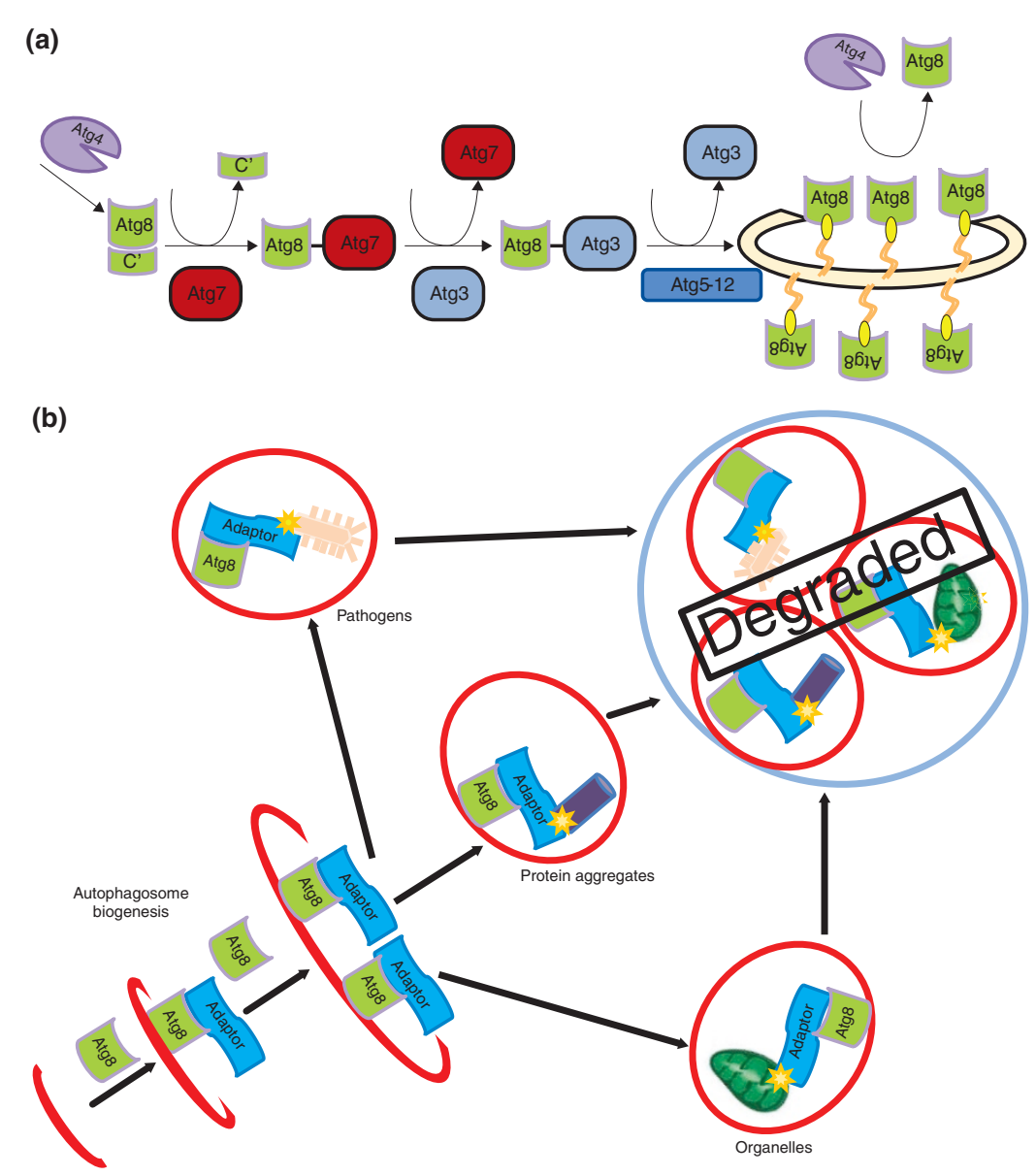

Figure 4. Atg8s in autophagy. (a) The conjugation of Atg8 proteins to phosphatidylethanolamine (PE) mediated by a series of steps involving Atg proteins. Following translation, Atg8 proteins are cleaved by the Atg 4 protease at the carboxyl terminus to expose a glycine residue. This glycine is then activated by the E1-like enzyme Atg7 and transferred to the E2-like enzyme Atg3. Finally, the conjugation of Atg8 proteins to PE is mediated by the E3-like complex Atg5-Atg12-Atg16. The association of Atg8 proteins with the autophagic membrane is reversible and is mediated by Atg4. (b) The role of Atg8 proteins in the autophagic process. Atg8 proteins are recruited to the autophagic membrane together with autophagic cargo adaptors. On the autophagic membrane Atg8 proteins are conjugated to PE lipids, enabling them to mediate membrane fusion events leading to autophagosome biogenesis. Different Atg8 proteins recruit distinct adaptors and are therefore responsible for the delivery of specific cargo (protein aggregates, organelles such as mitochondria and pathogens) for lysosomal degradation.

mediated by the cysteine protease Atg4, which is specific to Atg8 proteins [60,61]. The cleaved Atg8 is than processed by a ubiquitin-like conjugation machinery composed of Atg7, an E1-like enzyme [62], and Atg3, a specific E2-like ligase [63]. Unlike ubiquitin, which is conjugated to a protein, Atg8 is covalently conjugated to PE lipid through its carboxy-terminal exposed glycine [64]. Atg4 has a dual role, as it is also responsible for the de-conjugation of Atg8 from the autophagic membrane (Figure 4a) [64]. Similar to many other cytoplasm-tovacuole targeting and autophagic factors, Atg8 is localized to the pre-autophagosomal structure under basal and nitrogen depletion conditions [65], a process dependent on the phagophore resident complex Atg5-Atg12Atg16 [66]. The Atg5-Atg12 conjugate acts as an E3-like ligase, mediating the formation of Atg8-PE conjugate in vitro, suggesting a role for this complex in determining the Atg8 conjugation site in cells [67]. Recent evidence implicates Atg8 in both autophagic cargo recruitment and autophagosome biogenesis [18]. Atg8 has a key role in the cytoplasm-to-vacuole targeting pathway as it binds to the receptors Atg19 and Atg34, thereby mediating the recruitment of different cargo molecules into autophagosomes $[57,58]$. Atg8 also participates in formation of the autophagosome and is essential for elongation of the autophagic membrane $[68,69]$. This role was further established using an in vitro liposome-based system, where it can promote membrane fusion $[20,22]$. The roles of Atg8 in autophagosome biogenesis and in cargo recruitment overlap, as mutations that abolish Atg8 
binding to Atg19 receptor also disrupt autophagosome biogenesis $[70,71]$. In addition to its interaction with the conjugation proteins, Atg8 also binds to other autophagic factors, such as Atg1, which might regulate its recruitment and activity on the autophagic membrane [60]. Other, more general trafficking factors interact with Atg8, including Shp1, a substrate that recruits a cofactor of Cdc48. This interaction was suggested to control the formation of autophagosomes [72], indicating that Atg8 might provide a link between classical autophagic machinery and general trafficking factors that are crucial for autophagy.

Although mammalian Atg8 proteins were originally implicated in intracellular trafficking processes, they are all found within autophagosomes [73-75]. Collectively, they undergo similar post-translational modifications to those of yeast Atg8, but this is mediated by mammalian orthologs of Atg4, Atg7 and Atg3 [76]. It was suggested that Atg16L (the mammalian Atg16) determines the lipidation site of LC3 and serves as its E3 ligase [77]. Arrival of Atg8 proteins at the autophagic membrane depends on the hierarchical recruitment of numerous autophagic factors, including phosphatidylinositol-3phosphate-binding proteins [18].

Consistent with the presence of multiple Atg8 members in mammals, Atg4 also seems to have several homologs. These homologs show different specificities toward Atg8 proteins: Atg4B shows a broad spectrum for all family members [78,79], whereas Atg4A is specific to the GABARAP and GATE-16 subfamilies [80,81]. By contrast, Atg4C and Atg4D are less active and their role in the autophagic process has yet to be established [80]. Atg4 might function in pathways other than autophagy, as cleavage of Atg4D by caspase increases its activity and consequently promotes GABARAP-L1 processing [82]. Atg4 regulates a critical step in the autophagic process and is therefore subjected to regulation by reactive oxygen species, for example, which prevent it from reversing the conjugation of Atg 8 proteins to $\mathrm{PE}$ during autophagy [83].

Among Atg proteins, the Atg8 family is the only one associated with mature autophagosomes and members therefore serve as bona fide markers for this unique organelle. Thus, transgenic mice and tissue-culture cells expressing GFP-LC3 have been used to investigate autophagy $[84,85]$. However, the existence of numerous mammalian Atg8 proteins has hindered investigation of their precise role in autophagy. Several approaches aimed at disrupting the functioning of Atg8 proteins by preventing their conjugation to $\mathrm{PE}$ have therefore been used, including the generation of Atg3-null mice and expression of a dominant-negative mutant of the promiscuous protease Atg4B. These have led to the conclusion that PE-conjugated Atg8 proteins are active during autophagosome formation and are essential for the elongation and closure of the initial autophagic membrane, the phagophore [86-88]. A recent report [22] implicates both the LC3 and the GABARAP subfamilies in membrane fusion following conjugation to PE. This study [22] revealed that the first amino-terminal $\alpha$ helix of the Atg8 proteins was both essential and sufficient for this activity. Moreover, different characteristics within the amino termini of the Atg8 subfamilies are involved in their fusion activities. The first attempt to investigate the role of each Atg8 subfamily in autophagosome biogenesis was prompted by a study in which individual Atg8 proteins were knocked down [89]. Apparently, both the LC3 and the GABARAP/GATE-16 subfamilies are essential for autophagy, as they act at different stages of autophagosome formation: members of the LC3 subfamily are responsible for the elongation of the autophagic membrane, whereas GABARAP/GATE-16 subfamily members act downstream in a step coupled to dissociation of the Atg12-Atg5-Atg16L complex [89]. In addition to their direct role in fusion events during autophagosome biogenesis, Atg8 proteins have an indirect role in which their binding to diabetes- and obesity-regulated protein (DOR) and to tumor protein 53-induced nuclear protein 1 (TP53INP2), two proteins that shuttle between the nucleus and the cytoplasm, regulates autophagosome biogenesis [90,91].

The crucial role of Atg8 proteins in autophagosome biogenesis is controlled by numerous factors and modifications, such as acetylation and phosphorylation. Acetylation of the autophagic factors Atg5, Atg7, Atg8 and Atg12 is mediated by the acetyltransferase p300 and negatively regulates their activity [92]. Phosphorylation of LC3 seems to have a similar effect, as it was recently reported to negatively regulate autophagy [93]. Overall, Atg8s serve as key factors in the autophagic process by directly mediating membrane-remodeling processes and interacting with an extensive repertoire of proteins. These features are indispensable for the formation of an intact autophagosome and are therefore tightly regulated.

\section{Atg 8 proteins are involved in recruiting cargo into autophagosomes}

The role of Atg8s in autophagy extends beyond their function in autophagosome biogenesis. Like their Atg8 yeast ortholog, mammalian Atg8 proteins participate in cargo delivery into autophagosomes. Although the autophagic pathway in mammals has been referred to as a nonselective process, it seems that Atg8 proteins selectively target cytosolic components for lysosomal degradation [18]. Considerable progress in establishing this idea was achieved by the characterization of the ubiquitin-binding proteins p62/SQSTM1 [94], neighbor of Brca1 (Nbr1) [95], the Bcl2-related protein Nix [96,97], 
autophagy-linked FYVE protein (Alfy) [98-100], nuclear dot protein $52 \mathrm{kDa}$ (NDP52) [101], and Optineurin [102] as autophagic receptors. These adaptors bind simultaneously to Atg8 proteins and to ubiquitinated proteins, organelles, and in some cases pathogens $[18,94,103]$. The motif in p62 responsible for binding Atg8, the LC3interacting region (LIR, also known as Atg8-interacting motif, AIM) $[104,105]$, is common to other proteins that interact with Atg8 proteins, including Nbr1 [106], Atg3 [107], Nix [96] and the yeast cytoplasm-to-vacuole targeting receptor Atg19 [108].

Functional divergence of the Atg8 subfamilies is also inferred from specific interactions. Apparently, p62 binds both GATE-16 and LC3 in their soluble forms, but its interaction with LC3 but not with GATE-16 remains intact following their lipidation [21]. Thus, recruitment of p62 into autophagosomes specifically depends on LC3. This interaction, like other functions of Atg8 proteins, is dependent on the most variable region of these proteins, the amino terminus. Specificity of cargo recognition also applies to the GABARAP subfamily, as GABARAP-L1 binds to starch-binding-domain-containing protein 1 , a carrier of glycogen. This interaction results in the arrival of glycogen at the lysosome and is therefore suggested to regulate cellular glucose levels [109]. The role of Atg8s during the autophagic process is depicted in Figure $4 \mathrm{~b}$.

\section{Frontiers}

Atg8 proteins act in diverse intracellular trafficking and autophagy processes. Although the number of Atg8 genes increases if one compares organisms that diverged early with those that diverged late in evolution, their conjugation to PE on the autophagic membrane remains a common feature conserved through evolution. Considerable scientific advancement over the past few years has revealed many Atg8 functions during autophagy, but has also raised many new questions. One major question is how these factors orchestrate their dual role in membrane fusion and cargo recruitment into autophagosomes.

Although mammalian cells are thought to have as many as eight Atg8 proteins, the exact number is not clear, largely because these factors do not show a unique pattern of expression. Although the mammalian Atg8 subfamilies seem to act differently during the formation of autophagosomes, the need for up to four members from each subfamily has yet to be revealed. In particular, it is crucial to determine whether different members of one subfamily occupy the same autophagosomes or whether each member acts in a distinct autophagosome. This may help in deciphering whether autophagy, induced by different stress conditions, results in the formation of 'specialized' autophagosomes containing distinct Atg8 members. Moreover, substantial proteomic data are needed to establish the cargo specificity of each
Atg8 member. Selectivity of autophagy was recently reported for many organelles, such as peroxisomes (pexophagy), mitochondria (mitophagy) and ribosomes (ribophagy) [18]. It is feasible that different members of the Atg8 family are crucial for selective autophagy. The role of Atg8s in intracellular trafficking has not been extensively studied. Some lines of evidence show that the conjugation of Atg8s, specifically GABARAPs, to PE is essential for their activity. This should be further investigated by testing the requirement of the Atg8 conjugation system for Golgi-to-plasma-membrane trafficking.

One major obstacle in studying the role of individual Atg8 family members is their high sequence similarity. This feature reduces the specificity of antibodies, as antibodies against GABARAP, for example, may interact with GABARAP-L1. It is therefore crucial to exploit unique epitopes within these proteins to construct novel specific antibodies. Furthermore, the overexpression approach is not optimal as LC3 proteins tend to form aggregates when transiently expressed [110]. To overcome this pitfall, species that contain one Atg8 representative from each subfamily could be used to elucidate their role. Moreover, knockout mice of specific Atg8 subfamily members will help in dissecting these proteins' roles during development and in a tissue-specific manner. These are some of the questions and challenges that will be the focus of future studies.

\section{Acknowledgments}

ZE is the incumbent of the Harold Korda Chair of Biology and is supported in part by the Legacy Heritage Fund, and by the Louis Brause Philanthropic Fund. SP holds a Hermann and Lilly Schilling Foundation chair.

Published: 27 July 2011

References

1. Wood V, Gwilliam R, Rajandream MA, Lyne M, Lyne R, Stewart A, Sgouros J, Peat N, Hayles J, Baker S, Basham D, Bowman S, Brooks K, Brown D, Brown S, Chillingworth T, Churcher C, Collins M, Connor R, Cronin A, Davis P, Feltwell T, Fraser A, Gentles S, Goble A, Hamlin N, Harris D, Hidalgo J, Hodgson G, Holroyd S, et al:: The genome sequence of Schizosaccharomyces pombe. Nature 2002, 415:871-880.

2. VectorBase: I. scapularis [http://iscapularis.vectorbase.org/]

3. Insights into social insects from the genome of the honeybee Apis mellifera. Nature 2006, 443:931-949.

4. A Database of Drosophila Genes \& Genomes [http://flybase.org/]

5. Srivastava M, Simakov O, Chapman J, Fahey B, Gauthier ME, Mitros T, Richards GS, Conaco C, Dacre M, Hellsten U, Larroux C, Putnam NH, Stanke M, Adamska M, Darling A, Degnan SM, Oakley TH, Plachetzki DC, Zhai Y, Adamski M, Calcino A, Cummins SF, Goodstein DM, Harris C, Jackson DJ, Leys SP, Shu S, Woodcroft BJ, Vervoort M, Kosik KS, et al:: The Amphimedon queenslandica genome and the evolution of animal complexity. Nature 2010, 466:720-726.

6. King N, Westbrook MJ, Young SL, Kuo A, Abedin M, Chapman J, Fairclough S, Hellsten U, Isogai Y, Letunic I, Marr M, Pincus D, Putnam N, Rokas A, Wright KJ, Zuzow R, Dirks W, Good M, Goodstein D, Lemons D, Li W, Lyons JB, Morris A, Nichols S, Richter DJ, Salamov A, Sequencing JG, Bork P, Lim WA, Manning G, et al:: The genome of the choanoflagellate Monosiga brevicollis and the origin of metazoans. Nature 2008, 451:783-788.

7. Sláviková S, Shy G, Yao Y, Glozman R, Levanony H, Pietrokovski S, Elazar Z, Galili G: The autophagy-associated Atg8 gene family operates both under favorable growth conditions and under starvation stresses in Arabidopsis plants. J Exp Bot 2005, 56:2839-2849. 
8. Coyle JE, Qamar S, Rajashankar KR, Nikolov DB: Structure of GABARAP in two conformations: implications for GABA(A) receptor localization and tubulin binding. Neuron 2002, 33:63-74

9. Hu C, Zhang X, Teng YB, Hu HX, Li WF: Structure of autophagy-related protein Atg8 from the silkworm Bombyx mori. Acta Crystallogr Sect F Struct Biol Cryst Commun 2010, 66:787-790

10. Koopmann R, Muhammad K, Perbandt M, Betzel C, Duszenko M: Trypanosoma brucei ATG8: structural insights into autophagic-like mechanisms in protozoa. Autophagy 2009, 5:1085-1091.

11. Kouno T, Mizuguchi M, Tanida I, Ueno T, Kanematsu T, Mori Y, Shinoda H Hirata M, Kominami E, Kawano K: Solution structure of microtubuleassociated protein light chain 3 and identification of its functional subdomains. J Biol Chem 2005, 280:24610-24617.

12. Kumeta $H$, Watanabe $M$, Nakatogawa $H$, Yamaguchi M, Ogura K, Adachi W, Fujioka Y, Noda NN, Ohsumi Y, Inagaki F: The NMR structure of the autophagy-related protein Atg8. J Biomol NMR 2010, 47:237-241

13. Paz Y, Elazar Z, Fass D: Structure of GATE-16, membrane transport modulator and mammalian ortholog of autophagocytosis factor Aut7p. J Biol Chem 2000, 275:25445-25450.

14. Schwarten M, Stoldt M, Mohrluder J, Willbold D: Solution structure of Atg8 reveals conformational polymorphism of the $\mathrm{N}$-terminal domain. Biochem Biophys Res Commun 2010, 395:426-431.

15. Sugawara K, Suzuki NN, Fujioka Y, Mizushima N, Ohsumi Y, Inagaki F: The crystal structure of microtubule-associated protein light chain 3, a mammalian homologue of Saccharomyces cerevisiae Atg8. Genes Cells 2004, 9:611-618.

16. Noda NN, Ohsumi Y, Inagaki F: ATG systems from the protein structural point of view. Chem Rev 2009, 109:1587-1598.

17. Bavro VN, Sola M, Bracher A, Kneussel M, Betz H, Weissenhorn W: Crystal structure of the GABA(A)-receptor-associated protein, GABARAP. EMBO Rep 2002, 3:183-189.

18. Weidberg H, Shvets E, Elazar Z: Biogenesis and cargo selectivity of autophagosomes. Annu Rev Biochem 2011, 80:125-156.

19. Ichimura Y, Imamura Y, Emoto K, Umeda M, Noda T, Ohsumi Y: In vivo and in vitro reconstitution of Atg8 conjugation essential for autophagy. J Biol Chem 2004, 279:40584-40592.

20. Nakatogawa $\mathrm{H}$, Ichimura $Y$, Ohsumi Y: Atg8, a ubiquitin-like protein required for autophagosome formation, mediates membrane tethering and hemifusion. Cell 2007, 130:165-178.

21. Shvets E, Abada A, Weidberg H, Elazar Z: Dissecting the involvement of LC3B and GATE-16 in p62 recruitment into autophagosomes. Autophagy 2011, 7:683-688.

22. Weidberg H, Shpilka T, Shvets E, Abada A, Shimron F, Elazar Z: LC3 and GATE-16 $\mathrm{N}$ termini mediate membrane fusion processes required for autophagosome biogenesis. Dev Cell 2011, 20:444-454

23. He H, Dang Y, Dai F, Guo Z, Wu J, She X, Pei Y, Chen Y, Ling W, Wu C, Zhao S, Liu $J O, Y u L:$ Post-translational modifications of three members of the human MAP1LC3 family and detection of a novel type of modification for MAP1LC3B. J Biol Chem 2003, 278:29278-29287.

24. Xin Y, Yu L, Chen Z, Zheng L, Fu Q, Jiang J, Zhang P, Gong R, Zhao S: Cloning, expression patterns, and chromosome localization of three human and two mouse homologues of $\mathrm{GABA}(\mathrm{A})$ receptor-associated protein. Genomics 2001, 74:408-413.

25. Nemos C, Mansuy V, Vernier-Magnin S, Fraichard A, Jouvenot M, DelageMourroux R: Expression of gec1/GABARAPL1 versus GABARAP mRNAs in human: predominance of gec1/GABARAPL1 in the central nervous system. Brain Res Mol Brain Res 2003, 119:216-219.

26. Sagiv $Y$, Legesse-Miller $A$, Porat $A$, Elazar Z: GATE-16, a membrane transport modulator, interacts with NSF and the Golgi v-SNARE GOS-28. EMBO J 2000, 19:1494-1504

27. Egami Y, Kiryu-Seo S, Yoshimori T, Kiyama H: Induced expressions of Rab24 GTPase and LC3 in nerve-injured motor neurons. Biochem Biophys Res Commun 2005, 337:1206-1213.

28. Kirisako T, Baba M, Ishihara N, Miyazawa K, Ohsumi M, Yoshimori T, Noda T, Ohsumi Y: Formation process of autophagosome is traced with Apg8/ Aut7p in yeast. $J$ Cell Biol 1999, 147:435-446.

29. Zois CE, Giatromanolaki A, Kainulainen H, Botaitis S, Torvinen S, Simopoulos C, Kortsaris A, Sivridis E, Koukourakis MI: Lung autophagic response following exposure of mice to whole body irradiation, with and without amifostine. Biochem Biophys Res Commun 2011, 404:552-558.

30. van Zutphen T, Baerends RJ, Susanna KA, de Jong A, Kuipers OP, Veenhuis M, van der Klei IJ: Adaptation of Hansenula polymorpha to methanol: a transcriptome analysis. BMC Genomics 2010, 11:1.

31. Mammucari C, Milan G, Romanello V, Masiero E, Rudolf R, Del Piccolo P, Burden SJ, Di Lisi R, Sandri C, Zhao J, Goldberg AL, Schiaffino S, Sandri M: FoxO3 controls autophagy in skeletal muscle in vivo. Cell Metab 2007, 6:458-471.

32. Polager S, Ofir M, Ginsberg D: E2F1 regulates autophagy and the transcription of autophagy genes. Oncogene 2008, 27:4860-4864.

33. Sengupta A, Molkentin JD, Yutzey KE: FoxO transcription factors promote autophagy in cardiomyocytes. J Biol Chem 2009, 284:28319-28331.

34. Zhao J, Brault JJ, Schild A, Cao P, Sandri M, Schiaffino S, Lecker SH, Goldberg AL: FoxO3 coordinately activates protein degradation by the autophagic/ lysosomal and proteasomal pathways in atrophying muscle cells. Cell Metab 2007, 6:472-483

35. Elazar Z, Scherz-Shouval R, Shorer H: Involvement of LMA1 and GATE-16 family members in intracellular membrane dynamics. Biochim Biophys Acto 2003, 1641:145-156.

36. Legesse-Miller A, Sagiv Y, Porat A, Elazar Z: Isolation and characterization of a novel low molecular weight protein involved in intra-Golgi traffic. J Biol Chem 1998, 273:3105-3109.

37. Muller JM, Shorter J, Newman R, Deinhardt K, Sagiv Y, Elazar Z, Warren G, Shima DT: Sequential SNARE disassembly and GATE-16-GOS-28 complex assembly mediated by distinct NSF activities drives Golgi membrane fusion. J Cell Bio/ 2002, 157:1161-1173.

38. Kuznetsov SA, Gelfand VI: 18 kDa microtubule-associated protein: identification as a new light chain (LC-3) of microtubule-associated protein 1 (MAP-1). FEBS Lett 1987, 212:145-148.

39. Mann SS, Hammarback JA: Molecular characterization of light chain 3. A microtubule binding subunit of MAP1A and MAP1B. J Biol Chem 1994 269:11492-11497.

40. Wang H, Bedford FK, Brandon NJ, Moss SJ, Olsen RW: GABA(A)-receptorassociated protein links $G A B A(A)$ receptors and the cytoskeleton. Nature 1999, 397:69-72

41. Leil TA, Chen ZW, Chang CS, Olsen RW: GABAA receptor-associated protein traffics GABAA receptors to the plasma membrane in neurons. J Neurosci 2004, 24:11429-11438.

42. Chen ZW, Chang CS, Leil TA, Olsen RW: C-terminal modification is required for GABARAP-mediated GABA(A) receptor trafficking. J Neurosci 2007, 27:6655-6663.

43. Green F, O'Hare T, Blackwell A, Enns CA: Association of human transferrin receptor with GABARAP. FEBS Lett 2002, 518:101-106.

44. Nakamura T, Hayashi T, Nasu-Nishimura Y, Sakaue F, Morishita Y, Okabe T, Ohwada S, Matsuura K, Akiyama T: PX-RICS mediates ER-to-Golgi transport of the N-cadherin/beta-catenin complex. Genes Dev 2008, 22:1244-1256.

45. Kittler JT, Rostaing P, Schiavo G, Fritschy JM, Olsen R, Triller A, Moss SJ: The subcellular distribution of GABARAP and its ability to interact with NSF suggest a role for this protein in the intracellular transport of GABA(A) receptors. Mol Cell Neurosci 2001, 18:13-25.

46. Chen $L$, Wang $H$, Vicini $S$, Olsen RW: The gamma-aminobutyric acid type $A$ (GABAA) receptor-associated protein (GABARAP) promotes GABAA receptor clustering and modulates the channel kinetics. Proc Natl Acad SCi USA 2000, 97:11557-11562

47. Wang $\mathrm{H}$, Olsen RW: Binding of the GABA(A) receptor-associated protein (GABARAP) to microtubules and microfilaments suggests involvement of the cytoskeleton in GABARAPGABA(A) receptor interaction. J Neurochem 2000, 75:644-655

48. Chen C, Li JG, Chen Y, Huang P, Wang Y, Liu-Chen LY: GEC1 interacts with the kappa opioid receptor and enhances expression of the receptor. $J$ Biol Chem 2006, 281:7983-7993.

49. Mansuy V, Boireau W, Fraichard A, Schlick JL, Jouvenot M, Delage-Mourroux R: GEC1, a protein related to GABARAP, interacts with tubulin and GABA(A) receptor. Biochem Biophys Res Commun 2004, 325:639-648.

50. Chen C, Wang Y, Huang P, Liu-Chen LY: Effects of C-terminal modifications of GEC1 Protein and \{gamma\}-aminobutyric acid type A (GABAA) receptorassociated protein (GABARAP), two microtubule-associated proteins, on \{kappa\} opioid receptor expression. J Biol Chem 2011, 286:15106-15115

51. Chen Y, Chen C, Kotsikorou E, Lynch DL, Reggio PH, Liu-Chen LY: GEC1-kappa opioid receptor binding involves hydrophobic interactions: GEC1 has chaperone-like effect. J Biol Chem 2009, 284:1673-1685.

52. Tamura N, Oku M, Sakai Y: Atg 8 regulates vacuolar membrane dynamics in a lipidation-independent manner in Pichia pastoris. J Cell Sci 2010, 
123:4107-4116

53. Legesse-Miller A, Sagiv Y, Glozman R, Elazar Z: Aut7p, a soluble autophagic factor, participates in multiple membrane trafficking processes. $J \mathrm{Bio} / \mathrm{Chem}$ 2000, 275:32966-32973.

54. Harding TM, Morano KA, Scott SV, Klionsky DJ: Isolation and characterization of yeast mutants in the cytoplasm to vacuole protein targeting pathway. J Cell Biol 1995, 131:591-602.

55. Lang T, Schaeffeler E, Bernreuther D, Bredschneider M, Wolf DH, Thumm M: Aut $2 p$ and Aut7p, two novel microtubule-associated proteins are essential for delivery of autophagic vesicles to the vacuole. EMBO J 1998, 17:3597-3607.

56. Scott SV, Hefner-Gravink A, Morano KA, Noda T, Ohsumi Y, Klionsky DJ: Cytoplasm-to-vacuole targeting and autophagy employ the same machinery to deliver proteins to the yeast vacuole. Proc Natl Acad Sci U S A 1996, 93:12304-12308.

57. Lynch-Day MA, Klionsky DJ: The Cvt pathway as a model for selective autophagy. FEBS Lett 2010, 584:1359-1366.

58. Suzuki K, Kondo C, Morimoto M, Ohsumi Y: Selective transport of alphamannosidase by autophagic pathways: identification of a novel receptor Atg34p. J Biol Chem 2010, 285:30019-30025.

59. Huang WP, Scott SV, Kim J, Klionsky DJ: The itinerary of a vesicle component, Aut7p/Cvt5p, terminates in the yeast vacuole via the autophagy/Cvt pathways. J Biol Chem 2000, 275:5845-5851.

60. Kim J, Huang WP, Klionsky DJ: Membrane recruitment of Aut7p in the autophagy and cytoplasm to vacuole targeting pathways requires Aut $1 p$, Aut2p, and the autophagy conjugation complex. J Cell Biol 2001, 152:51-64.

61. Kirisako T, Ichimura Y, Okada H, Kabeya Y, Mizushima N, Yoshimori T, Ohsumi M, Takao T, Noda T, Ohsumi Y: The reversible modification regulates the membrane-binding state of Apg8/Aut7 essential for autophagy and the cytoplasm to vacuole targeting pathway. J Cell Bio/ 2000, 151:263-276.

62. Tanida I, Mizushima N, Kiyooka M, Ohsumi M, Ueno T, Ohsumi Y, Kominami E: Apg7p/Cvt2p: A novel protein-activating enzyme essential for autophagy. Mol Biol Cell 1999, 10:1367-1379.

63. Schlumpberger M, Schaeffeler E, Straub M, Bredschneider M, Wolf DH, Thumm M: AUT1, a gene essential for autophagocytosis in the yeast Saccharomyces cerevisiae. J Bacterio/ 1997, 179:1068-1076.

64. Ichimura Y, Kirisako T, Takao T, Satomi Y, Shimonishi Y, Ishihara N, Mizushima N, Tanida I, Kominami E, Ohsumi M, Noda T, Ohsumi Y: A ubiquitin-like system mediates protein lipidation. Nature 2000, 408:488-492

65. Suzuki K, Ohsumi Y: Current knowledge of the pre-autophagosomal structure (PAS). FEBS Lett 2010, 584:1280-1286

66. Suzuki K, Kirisako T, Kamada Y, Mizushima N, Noda T, OhsumiY. The preautophagosomal structure organized by concerted functions of APG genes is essential for autophagosome formation. EMBO J 2001, 20:5971-5981.

67. Hanada T, Noda NN, Satomi Y, Ichimura Y, Fujioka Y, Takao T, Inagaki F, Ohsumi Y: The Atg12-Atg5 conjugate has a novel E3-like activity for protein lipidation in autophagy. J Biol Chem 2007, 282:37298-37302.

68. Abeliovich H, Dunn WA Jr, Kim J, Klionsky DJ: Dissection of autophagosome biogenesis into distinct nucleation and expansion steps. J Cell Bio/ 2000 151:1025-1034.

69. Xie Z, Nair U, Klionsky DJ: Atg8 controls phagophore expansion during autophagosome formation. Mol Biol Cell 2008, 19:3290-3298.

70. Amar N, Lustig G, Ichimura Y, Ohsumi Y, Elazar Z: Two newly identified sites in the ubiquitin-like protein Atg8 are essential for autophagy. EMBO Rep 2006, 7:635-642.

71. Ho KH, Chang HE, Huang WP: Mutation at the cargo-receptor binding site of Atg8 also affects its general autophagy regulation function. Autophagy 2009, 5:461-471.

72. Krick R, Bremer S, Welter E, Schlotterhose P, Muehe Y, Eskelinen EL, Thumm M: Cdc48/p97 and Shp1/p47 regulate autophagosome biogenesis in concert with ubiquitin-like Atg8. J Cell Biol 2010, 190:965-973.

73. Chakrama FZ, Seguin-Py S, Le Grand JN, Fraichard A, Delage-Mourroux R, Despouy G, Perez V, Jouvenot M, Boyer-Guittaut M: GABARAPL1 (GEC1) associates with autophagic vesicles. Autophagy 2010, in press..

74. Kabeya Y, Mizushima N, Ueno T, Yamamoto A, Kirisako T, Noda T, Kominami E, Ohsumi Y, Yoshimori T: LC3, a mammalian homologue of yeast Apg8p, is localized in autophagosome membranes after processing. EMBO J 2000 , 19:5720-5728.

75. Kabeya Y, Mizushima N, Yamamoto A, Oshitani-Okamoto S, Ohsumi Y, Yoshimori T: LC3, GABARAP and GATE16 localize to autophagosomal membrane depending on form-II formation. J Cell Sci 2004, 117:2805-2812

76. Tanida I, Ueno T, Kominami E: LC3 conjugation system in mammalian autophagy. Int J Biochem Cell Biol 2004, 36:2503-2518.

77. Fujita N, Itoh T, Omori H, Fukuda M, Noda T, Yoshimori T: The Atg16L complex specifies the site of LC3 lipidation for membrane biogenesis in autophagy. Mol Biol Cell 2008, 19:2092-2100.

78. Hemelaar J, Lelyveld VS, Kessler BM, Ploegh HL: A single protease, Apg4B, is specific for the autophagy-related ubiquitin-like proteins GATE-16, MAP1 LC3, GABARAP, and Apg8L. J Biol Chem 2003, 278:51841-51850.

79. Tanida I, Ueno T, Kominami E: Human light chain 3/MAP1LC3B is cleaved at its carboxyl-terminal Met121 to expose Gly120 for lipidation and targeting to autophagosomal membranes. J Bio/ Chem 2004, 279:47704-47710.

80. Li M, Hou Y, Wang J, Chen X, Shao ZM, Yin XM: Kinetics comparisons of mammalian Atg 4 homologues indicate selective preferences toward diverse Atg8 substrates. J Biol Chem 2011, 286:7327-7338.

81. Scherz-Shouval R, Sagiv $Y$, Shorer $\mathrm{H}$, Elazar Z: The $\mathrm{COOH}$ terminus of GATE-16, an intra-Golgi transport modulator, is cleaved by the human cysteine protease HsApg4A.J Biol Chem 2003, 278:14053-14058.

82. Betin VM, Lane JD: Caspase cleavage of Atg4D stimulates GABARAP-L1 processing and triggers mitochondrial targeting and apoptosis. J Cell SCi 2009, 122:2554-2566.

83. Scherz-Shouval R, Shvets E, Fass E, Shorer H, Gil L, Elazar Z: Reactive oxygen species are essential for autophagy and specifically regulate the activity of Atg4. EMBO J 2007, 26:1749-1760.

84. Mizushima N, Yamamoto A, Matsui M, Yoshimori T, Ohsumi Y: In vivo analysis of autophagy in response to nutrient starvation using transgenic mice expressing a fluorescent autophagosome marker. Mol Biol Cell 2004, 15:1101-1111

85. Tanida I, Waguri S: Measurement of autophagy in cells and tissues. Methods Mol Biol 2010, 648:193-214.

86. Fujita N, Hayashi-Nishino M, Fukumoto H, Omori H, Yamamoto A, Noda T, Yoshimori T: An Atg4B mutant hampers the lipidation of LC3 paralogues and causes defects in autophagosome closure. Mol Biol Cell 2008, 19:4651-4659.

87. Hayashi-Nishino M, Fujita N, Noda T, Yamaguchi A, Yoshimori T, Yamamoto A: A subdomain of the endoplasmic reticulum forms a cradle for autophagosome formation. Nat Cell Bio/ 2009, 11:1433-1437.

88. Sou YS, Waguri S, Iwata J, Ueno T, Fujimura T, Hara T, Sawada N, Yamada A, Mizushima N, Uchiyama Y, Kominami E, Tanaka K, Komatsu M:The Atg8 conjugation system is indispensable for proper development of autophagic isolation membranes in mice. Mol Biol Cell 2008, 19:4762-4775.

89. Weidberg H, Shvets E, Shpilka T, Shimron F, Shinder V, Elazar Z: LC3 and GATE-16/GABARAP subfamilies are both essential yet act differently in autophagosome biogenesis. EMBO J 2010, 29:1792-1802.

90. Mauvezin C, Orpinell M, Francis VA, Mansilla F, Duran J, Ribas V, Palacin M Boya P, Teleman AA, Zorzano A: The nuclear cofactor DOR regulates autophagy in mammalian and Drosophila cells. EMBO Rep 2010, 11:37-44.

91. Nowak J, Archange C, Tardivel-Lacombe J, Pontarotti P, Pebusque MJ, Vaccaro MI, Velasco G, Dagorn JC, lovanna JL: The TP53INP2 protein is required for autophagy in mammalian cells. Mol Biol Cell 2009, 20:870-881.

92. Lee $\mid H$, Finkel T: Regulation of autophagy by the p300 acetyltransferase. J Biol Chem 2009, 284:6322-6328.

93. Cherra SJ, 3rd, Kulich SM, Uechi G, Balasubramani M, Mountzouris J, Day BW, Chu CT: Regulation of the autophagy protein LC3 by phosphorylation. $J$ Cell Biol 2010, 190:533-539.

94. Bjorkoy G, Lamark T, Brech A, Outzen H, Perander M, Overvatn A, Stenmark H, Johansen T: p62/SQSTM1 forms protein aggregates degraded by autophagy and has a protective effect on huntingtin-induced cell death. J Cell Bio/ 2005, 171:603-614

95. Kirkin V, LamarkT, Sou YS, Bjørkøy G, Nunn JL, Bruun JA, Shvets E, McEwan DG, Clausen TH, Wild P, Bilusic I, Theurillat JP, Øvervatn A, Ishii T, Elazar Z, Komatsu M, Dikic I, Johansen T: A role for NBR1 in autophagosomal degradation of ubiquitinated substrates. Mo/ Cell 2009, 33:505-516.

96. Novak I, Kirkin V, McEwan DG, Zhang J, Wild P, Rozenknop A, Rogov V, Löhr F, Popovic D, Occhipinti A, Reichert AS, Terzic J, Dötsch V, Ney PA, Dikic I: Nix is a selective autophagy receptor for mitochondrial clearance. EMBO Rep 2010 11:45-51.

97. Schwarten M, Mohrluder J, Ma P, Stoldt M, Thielmann Y, Stangler T, Hersch N Hoffmann B, Merkel R, Willbold D: Nix directly binds to GABARAP: a possible crosstalk between apoptosis and autophagy. Autophagy 2009, 5:690-698. 
98. Filimonenko M, Stuffers S, Raiborg C, Yamamoto A, Malerod L, Fisher EM, Isaacs A, Brech A, Stenmark H, Simonsen A: Functional multivesicular bodies are required for autophagic clearance of protein aggregates associated with neurodegenerative disease. J Cell Bio/ 2007, 179:485-500.

99. Clausen TH, Lamark T, Isakson P, Finley K, Larsen KB, Brech A, Øvervatn A, Stenmark H, Bjørkøy G, Simonsen A, Johansen T: p62/SQSTM1 and ALFY interact to facilitate the formation of $\mathrm{p} 62$ bodies/ALIS and their degradation by autophagy. Autophagy 2010, 6:330-344.

100. Filimonenko M, Isakson P, Finley KD, Anderson M, Jeong H, Melia TJ, Bartlett BJ, Myers KM, Birkeland HC, LamarkT, Krainc D, Brech A, Stenmark H, Simonsen A, Yamamoto A: The selective macroautophagic degradation of aggregated proteins requires the PI3P-binding protein Alfy. Mol Cell 2010 38:265-279.

101. Thurston TL, Ryzhakov G, Bloor S, von Muhlinen N, Randow F: The TBK1 adaptor and autophagy receptor NDP52 restricts the proliferation of ubiquitin-coated bacteria. Nat Immuno/ 2009, 10:1215-1221.

102. Wild P, Farhan H, McEwan DG, Wagner S, Rogov W, Brady NR, Richter B, Korac J, Waidmann O, Choudhary C, Dötsch V, Bumann D, Dikic I: Phosphorylation of the autophagy receptor optineurin restricts Salmonella growth. Science 2011, 333:228-233.

103. Shvets E, Fass E, Scherz-Shouval R, Elazar Z: The N-terminus and Phe52 residue of LC3 recruit p62/SQSTM1 into autophagosomes. J Cell Sci 2008, 121:2685-2695

104. Ichimura Y, Kumanomidou T, Sou YS, Mizushima T, Ezaki J, Ueno T, Kominami E, Yamane T, Tanaka K, Komatsu M: Structural basis for sorting mechanism of p62 in selective autophagy. J Biol Chem 2008, 283:22847-22857.

105. Pankiv S, Clausen TH, LamarkT, Brech A, Bruun JA, Outzen H, Overvatn A, Bjorkoy G, Johansen T: p62/SQSTM1 binds directly to Atg8/LC3 to facilitate degradation of ubiquitinated protein aggregates by autophagy. J Biol Chem 2007, 282:24131-24145.

106. Kraft C, Peter M, Hofmann K: Selective autophagy: ubiquitin-mediated recognition and beyond. Nat Cell Biol 2010, 12:836-841.

107. Yamaguchi M, Noda NN, Nakatogawa H, Kumeta H, Ohsumi Y, Inagaki F: Autophagy-related protein 8 (Atg8) family interacting motif in Atg3 mediates the Atg3-Atg8 interaction and is crucial for the cytoplasm-to- vacuole targeting pathway. J Biol Chem 2010, 285:29599-29607.

108. Noda NN, Kumeta H, Nakatogawa H, Satoo K, Adachi W, Ishii J, Fujioka Y, Ohsumi Y, Inagaki F: Structural basis of target recognition by Atg8/LC3 during selective autophagy. Genes Cells 2008, 13:1211-1218.

109. Jiang S, Heller B, Tagliabracci VS, Zhai L, Irimia JM, DePaoli-Roach AA, Wells CD, Skurat AV, Roach PJ: Starch binding domain-containing protein 1/ genethonin 1 is a novel participant in glycogen metabolism. J Bio/ Chem 2010, 285:34960-34971.

110. Kuma A, Matsui M, Mizushima N: LC3, an autophagosome marker, can be incorporated into protein aggregates independent of autophagy: caution in the interpretation of LC3 localization. Autophagy 2007, 3:323-328.

111. Ruiz-Trillo I, Roger AJ, Burger G, Gray MW, Lang BF: A phylogenomic investigation into the origin of metazoa. Mol Biol Evol 2008, 25:664-672.

112. Salzberg Y, Eldar T, Karminsky OD, Itach SB, Pietrokovski S, Don J: Meig1 deficiency causes a severe defect in mouse spermatogenesis. Dev Biol 2010, 338:158-167.

113. Schneider TD, Stephens RM: Sequence logos: a new way to display consensus sequences. Nucleic Acids Res 1990, 18:6097-6100.

114. Marchler-Bauer A, Lu S, Anderson JB, Chitsaz F, Derbyshire MK, DeWeeseScott C, Fong JH, Geer LY, Geer RC, Gonzales NR, Gwadz M, Hurwitz DI, Jackson JD, Ke Z, Lanczycki CJ, Lu F, Marchler GH, Mullokandov M, Omelchenko MV, Robertson CL, Song JS, Thanki N, Yamashita RA, Zhang D, Zhang N, Zheng C, Bryant SH: CDD: a Conserved Domain Database for the functional annotation of proteins. Nucleic Acids Res 2011, 39:D225-D229.

115. Finn RD, Mistry J, Tate J, Coggill P, Heger A, Pollington JE, Gavin OL, Gunasekaran P, Ceric G, Forslund K, Holm L, Sonnhammer EL, Eddy SR, Bateman A: The Pfam protein families database. Nucleic Acids Res 2010 38:D211-D222

\section{doi:10.1186/gb-2011-12-7-226}

Cite this article as: Shpilka T, et al.: Atg8: an autophagy-related ubiquitinlike protein family. Genome Biology 2011, 12:226. 